\title{
Surgical Treatment, Oral Rehabilitation, and Orthognathic Surgery After Failure of Pharmacologic Treatment of Central Giant Cell Lesion: A Case Report
}

Renato Luiz Maia Nogueira, DDS, MSc, PhD ${ }^{*}$ Rafael Lima Verde Osterne, DDS, MSc Roberta Barroso Cavalcante, DDS, MSc, PbD, $\ddagger$ and

Ricardo Teixeira Abreu, DDS, MSc, PbD

\begin{abstract}
Although pharmacologic treatments for central giant cell lesions have gained much emphasis, these treatment modalities do not always have successful outcomes, and surgical treatment may be necessary. The purpose of the present study was to report a case of aggressive central giant cell lesion initially treated by nonsurgical methods without satisfactory results, necessitating segmental mandibular resection for definitive treatment and oral rehabilitation. A 20-year-old woman was diagnosed with an aggressive central giant cell lesion in the mandible. The patient was first treated with intralesional corticosteroid injections. Subsequently, the lesion increased in size. Therefore, a second pharmacologic treatment was proposed with salmon calcitonin nasal spray, but no signs of a treatment response were noted. Because of the lack of response, surgical excision was performed, and a mandibular reconstruction plate was installed. At 12 months after surgical resection, the patient underwent mandibular reconstruction with bone grafts. After 6 months, 7 dental implants were installed, and fixed prostheses were made. After installation of the prostheses, the patient experienced persistent mandibular laterognathism, and a mandibular orthognathic surgery was performed to correct the laterognathia. The follow-up examination 4 years after orthognathic surgery showed no signs of recurrence and good facial symmetry.

(C) 2016 American Association of Oral and Maxillofacial Surgeons

J Oral Maxillofac Surg 74:2567.e1-2567.e10, 2016
\end{abstract}

Central giant cell lesion (CGCL) is a benign, intraosseous proliferative lesion composed of multinucleated giant cells (MGCs) in a cellular background composed of mononucleated stromal cells with ovoid or spindleshaped nuclei. ${ }^{1}$ This tumor-like lesion occurs in both jaws, but the mandible is more often involved than the maxilla, and most cases appear before the age of 30 years. ${ }^{1,2}$

The etiology of CGCL remains uncertain. Aggressive cases with rapid growth, tissue destruction, and high rates of recurrence suggest a neoplastic origin, but cases reported after tooth extraction suggest a reactive
*Associate Professor, Department of Dental Clinic, Discipline of Oral and Maxillofacial Surgery and Stomatology, Federal University of Ceara School of Dentistry, Fortaleza, Brazil; Oral and Maxillofacial Surgeon, Department of Oral and Maxillofacial Surgery, Memorial Batista Hospital, Fortaleza, Brazil.

†Assistant Professor, Department of Pathology, Fortaleza University School of Medicine, Fortaleza, Brazil; PhD Student, Federal University of Ceara School of Dentistry, Fortaleza, Brazil.

$\ddagger$ Associate Professor, Department of Oral Pathology, Fortaleza University School of Dentistry, Fortaleza, Brazil.

$\S$ Associate Professor, São Leopoldo Mandic, Fortaleza, Brazil.
Address correspondence and reprint requests to Dr Osterne: Department of Pathology, Universidade de Fortaleza, Ave Washington Soares, 1321, PO Box 1258, Edson Queiroz, Fortaleza, Ceará 60811-905, Brazil; e-mail: rlimaverde@unifor.br Received July 282016

Accepted August 222016

(C) 2016 American Association of Oral and Maxillofacial Surgeons 0278-2391/16/30772-8 http://dx.doi.org/10.1016/i.joms.2016.08.038 

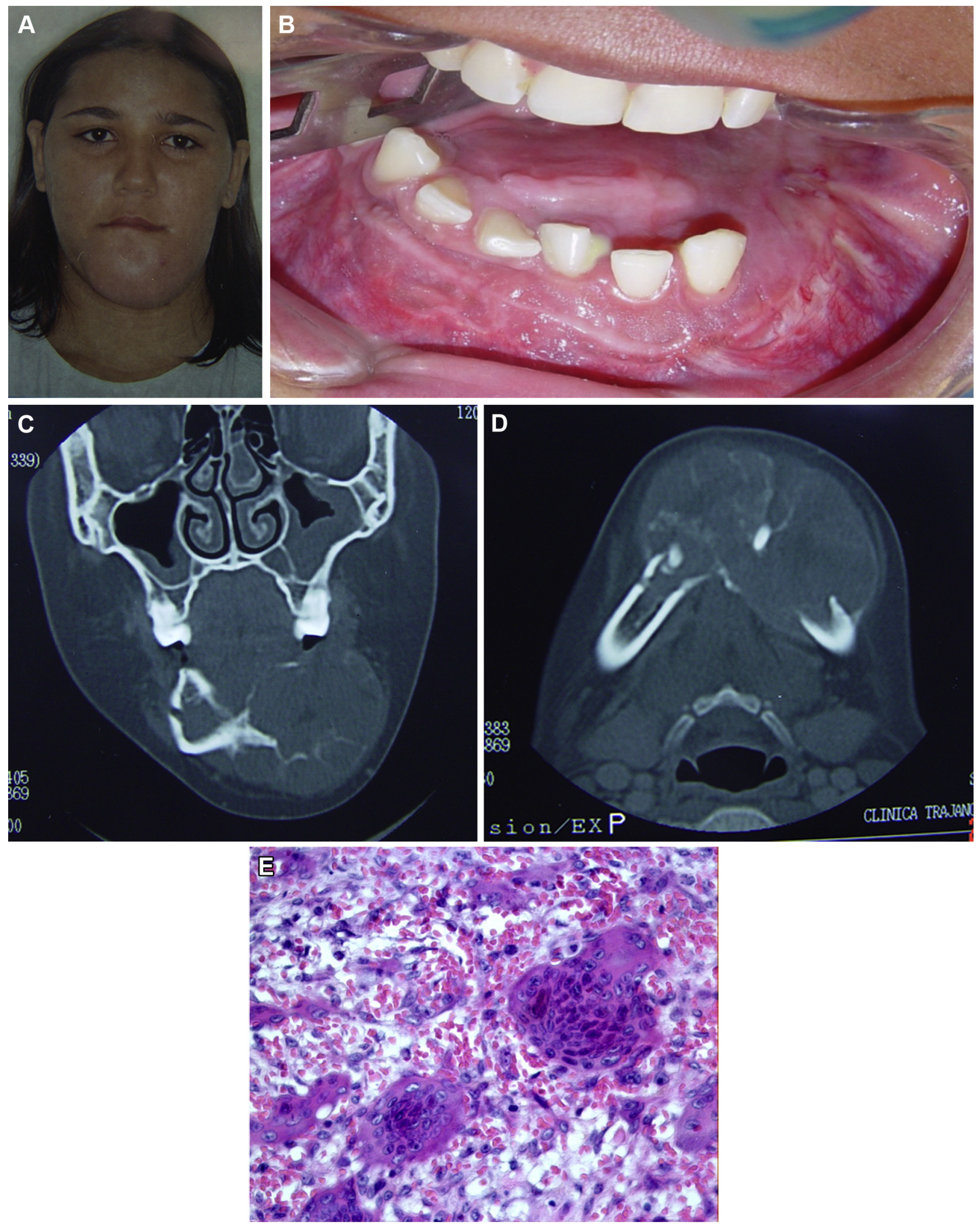

FIGURE 1. A, A 20-year-old female presented with swelling in the region of the symphysis and left mandibular body. $B$, The intraoral clinical examination revealed an obliteration of the buccal sulcus, elevation of the floor of the mouth, and tooth displacement. $C, D, A$ computed tomography scan revealed the presence of a multilocular osteolytic lesion extending from the region of teeth mandibular left first molar to mandibular right lateral incisor, with tooth displacement. $E$, An incisional biopsy revealed the presence of multinucleated giant cells embedded in a cellularized background of cells with spindle-shaped and sometimes ovoid nuclei. The patient provided written consent for publication of her clinical photographs. 

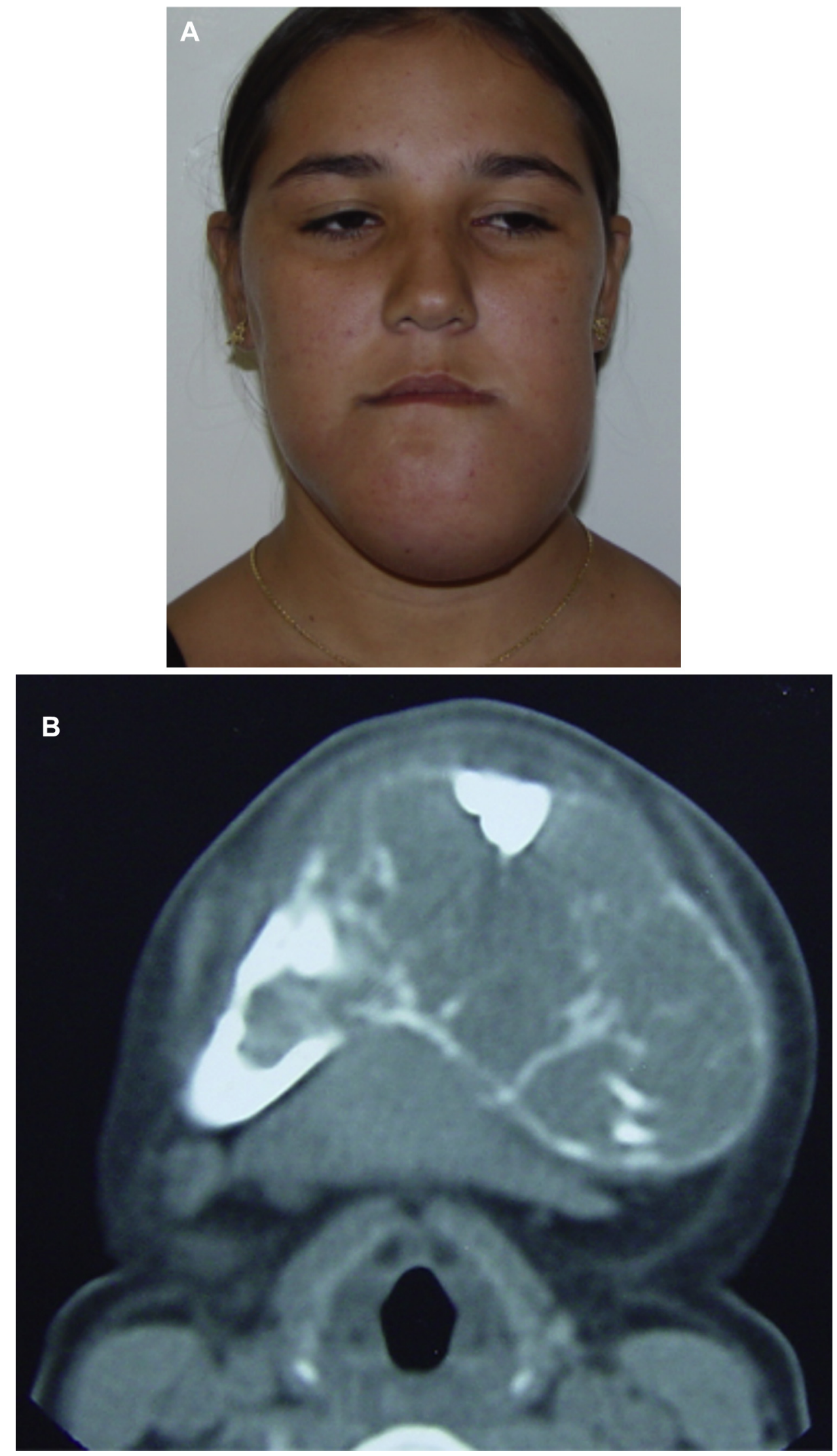

FIGURE 2. Views after the initial treatment with intralesional corticosteroid injections and calcitonin, revealing the increase in the volume of the osteolytic lesion. A, Extraoral view. B, Computed tomography scan. 

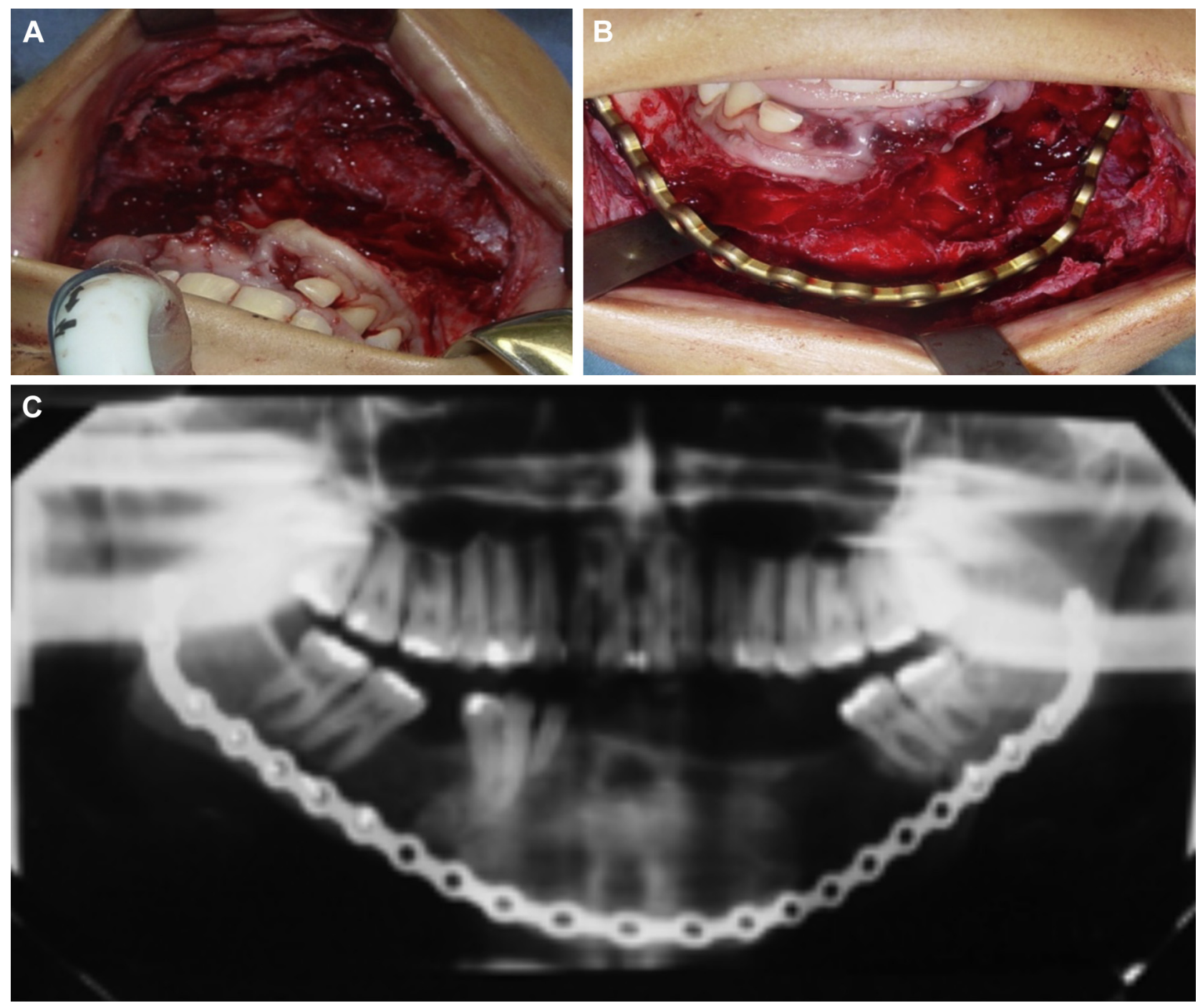

FIGURE 3. A, Surgical excision of central giant cell lesion with the patient under general anesthesia. $B$, Installation of a mandibular reconstruction plate. C, Postoperative panoramic radiograph.

Maia Nogueira et al. Treatment of CGCL. J Oral Maxillofac Surg 2016.

lesion. ${ }^{3}$ Chuong et $\mathrm{al}^{2}$ classified CGCL into aggressive and nonaggressive lesions. Nonaggressive lesions present as slow and asymptomatic growths without cortical perforation. Aggressive lesions are characterized by swellings of rapid growth, which can be associated with pain, tooth mobility, root resorption, and cortical perforation.

Surgery is still considered the first therapeutic option for CGCL; however, new nonsurgical approaches have gained much emphasis, including calcitonin, ${ }^{4}$ intralesional corticosteroid injections, ${ }^{5}$ antiangiogenic agents, ${ }^{6-8}$ and novel receptor activator of nuclear factor kappa-B ligand (RANKL) inhibitors. . $^{9-11}$

The purpose of the present study was to report a case of aggressive CGCL in which the initial treatment was nonoperative but without satisfactory results, necessitating segmental mandibular resection for definitive treatment. The oral rehabilitation is also reported.

\section{Case Report}

In July 2003, a 20-year-old female patient presented to the oral and maxillofacial surgery department with complaints of painful swelling in the mandible with rapid growth. Her medical and family histories were noncontributory. The extraoral clinical examination revealed considerable swelling in the region of the symphysis and left mandibular body. No associated lymphadenopathy was present. The intraoral clinical examination revealed an obliteration of the buccal sulcus, elevation of the floor of the mouth, and tooth displacement. Imaging studies revealed the presence of a multilocular osteolytic lesion extending from the 

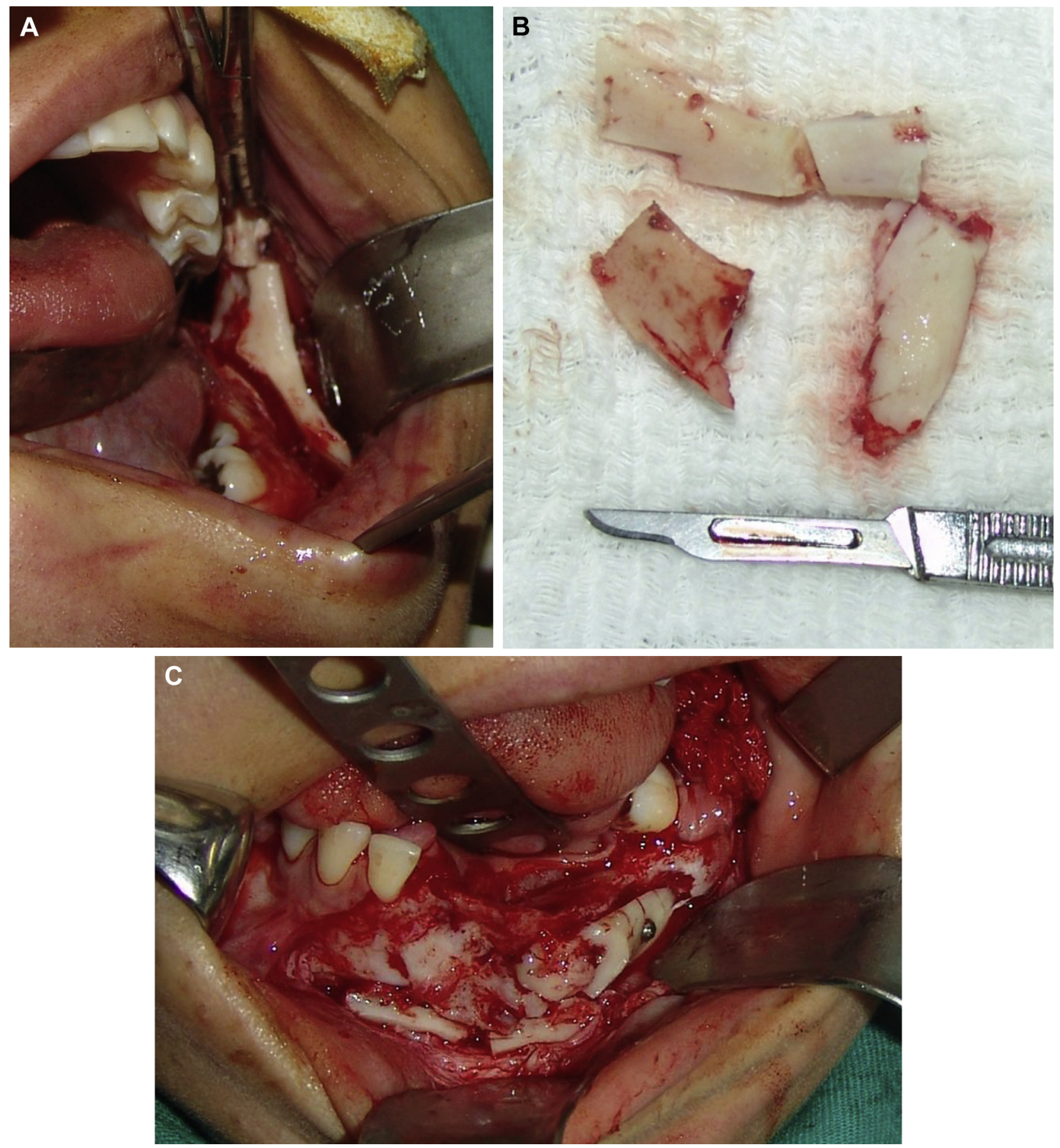

FIGURE 4. At 12 months after resection, mandibular reconstruction surgery was performed with the patient under general anesthesia. $A, B$, Grafts were removed from the mandibular ramus bilaterally and $C$, fixed in the region of the mandibular defect.

Maia Nogueira et al. Treatment of CGCL. J Oral Maxillofac Surg 2016.

region of mandibular left first molar to mandibular right lateral incisor, with tooth displacement and perforation of the cortical bone. An incisional biopsy revealed the presence of MGCs embedded in a cellularized background of cells with spindle-shaped and sometimes ovoid nuclei (Fig 1). Laboratory tests revealed normal serum calcium, phosphate, and para- thormone, finalizing the diagnosis of an aggressive CGCL of the jaws.

The proposed initial treatment was intralesional application of corticosteroids using the following protocol: 1 biweekly application of triamcinolone hexacetonide $20 \mathrm{mg} / \mathrm{mL}$, diluted in an anesthetic solution of $2 \%$ lidocaine/epinephrine $1: 200,000$ in a ratio of $1: 1$; 

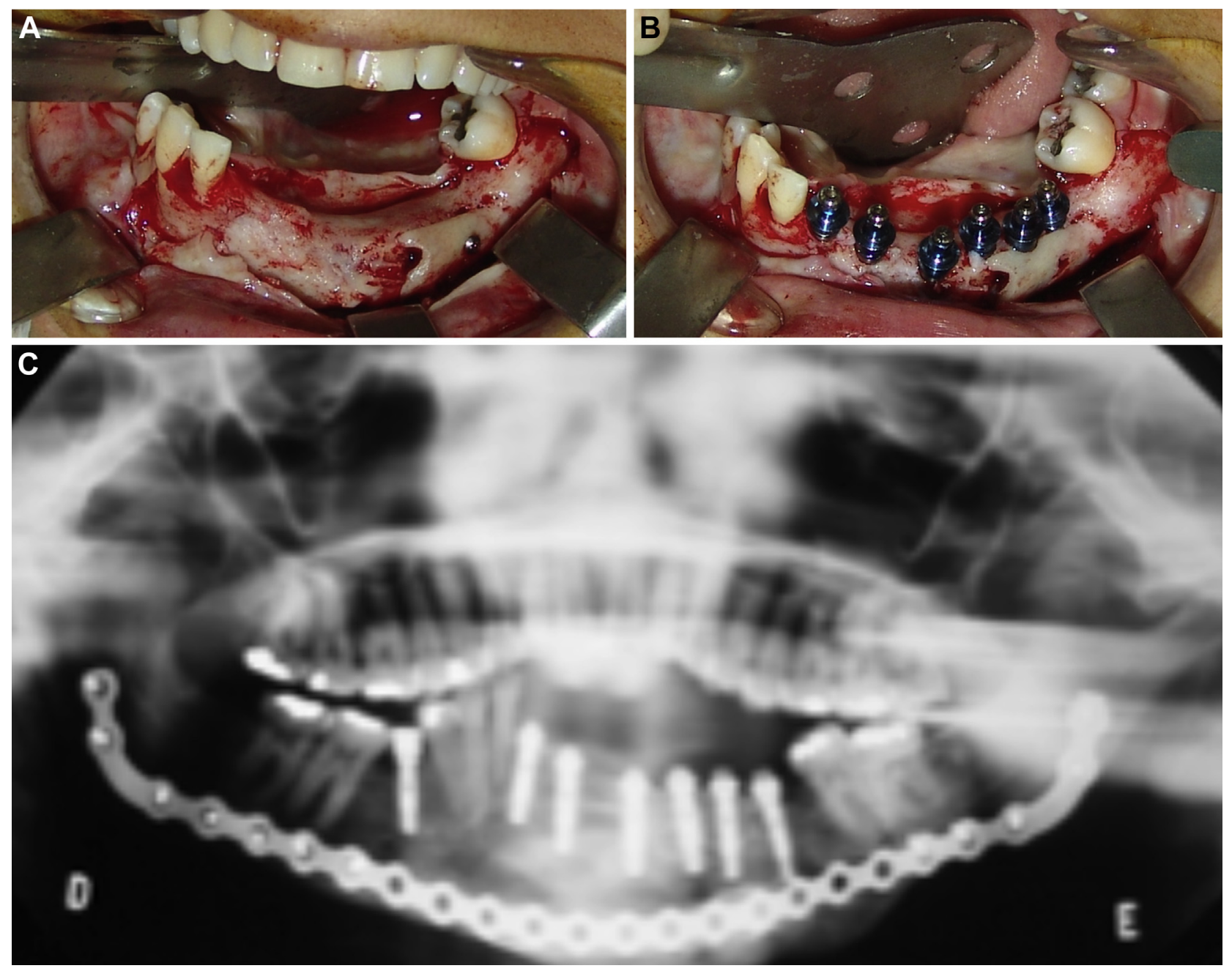

FIGURE 5. $A, B$, At 6 months after graft placement, 7 dental implants were installed in the mandible. C, Postoperative panoramic radiograph.

Maia Nogueira et al. Treatment of CGCL. J Oral Maxillofac Surg 2016.

$1.0 \mathrm{~mL}$ of the solution was infiltrated for every $1 \mathrm{~cm}^{2}$ of radiolucent area of the lesion, totaling 6 biweekly applications. In November 2003, after completion of the protocol, the treatment response was considered negative because her symptoms had not ceased, the lesion had continued to increase, no increase in radiopacity was observed, and the resistance to infiltrating the solution had not increased. In fact, the lesion had increased considerably in size (Fig 2). Owing to the lack of response to the intralesional corticosteroid injections, the use of salmon calcitonin nasal spray was proposed at a dose of $200 \mathrm{IU} /$ day. The treatment lasted 12 months, but no signs of a response to treatment were seen.

After failure of the corticosteroid injections and calcitonin spray, it was decided to perform surgical excision by intraoral access with the patient under general anesthesia in November 2004. During resection, the teeth involved in the lesion were removed, and, because of the loss of the mandibular segment, a mandibular reconstruction plate was installed and wrapped with periosteum (Fig 3). The postoperative period was uneventful. Twelve months after the surgical resection, no recurrence of the CGCL had developed, and the patient underwent mandibular reconstruction with bone grafts under general anesthesia. On reopening the access, some bone had formed on the reconstruction plate, which had been wrapped under the periosteum. The grafts were removed from the mandibular ramus and fixed to the previously formed bone (Fig 4). At 6 months after the bone graft procedure, 7 dental implants (external hexagon of 4.1-mm platform; Biomet 3i, Palm Beach Garden, FL) were installed in the mandible with the aid of surgical guides for implant positioning (Fig 5). After 5 months, fixed prostheses were made.

After installation of the prostheses, the patient experienced persistent mandibular laterognathism (Fig 6). Thus, in August 2012, mandibular orthognathic surgery was performed to correct the laterognathia. Under general anesthesia, the mandibular reconstruction plate was removed, and bilateral sagittal split ramus 

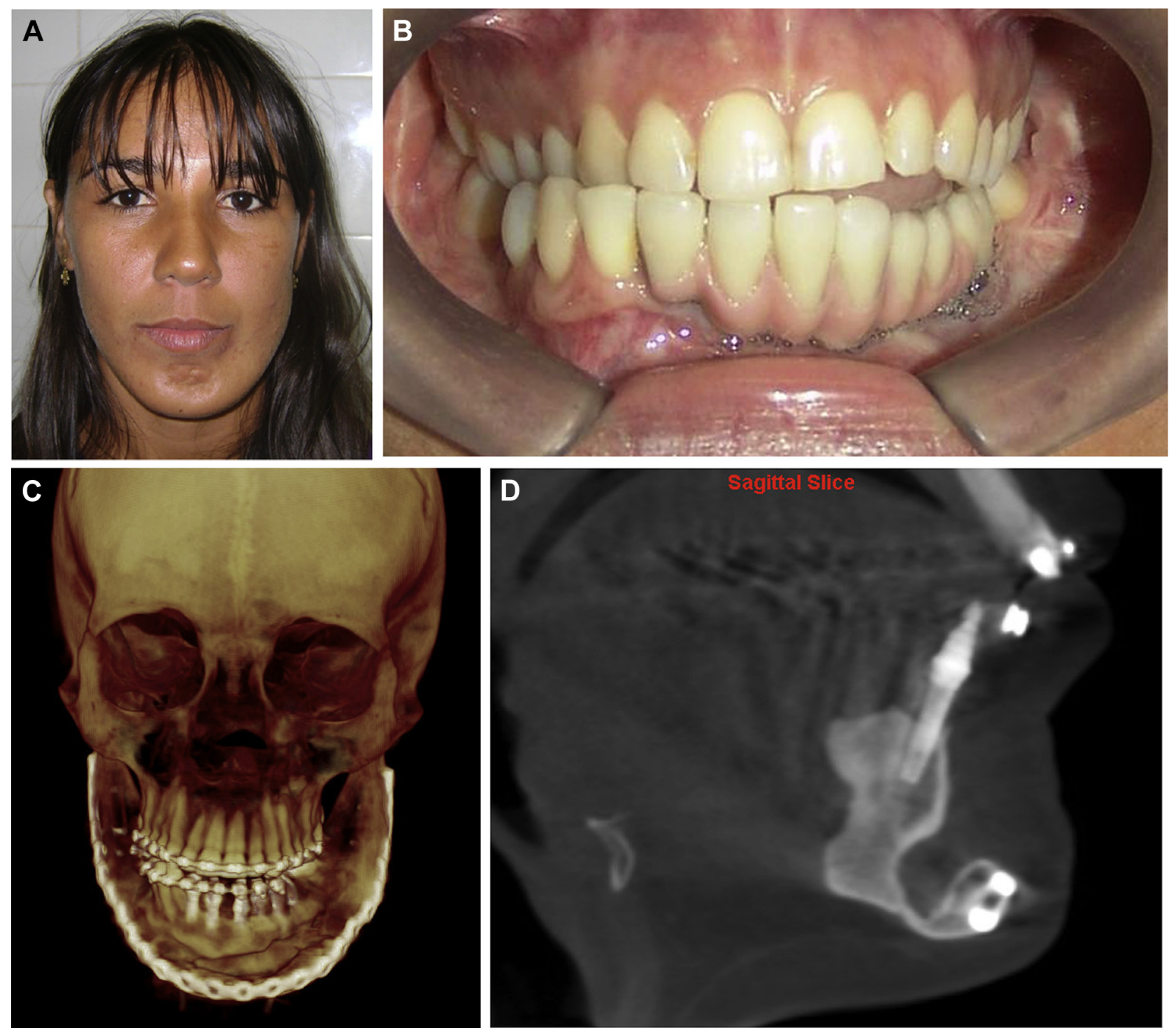

FIGURE 6. At 5 months after dental implant installation, fixed prostheses were made. $A$, Extraoral view, $B$, intraoral view, and $C$, 3-dimensional reconstruction of cone beam computed tomography (CBCT) scan. $D$, A sagittal slice of a CBCT scan showing the residual mandibular bone defect.

Maia Nogueira et al. Treatment of CGCL. J Oral Maxillofac Surg 2016.

osteotomies were performed. The jaw was repositioned and fixed with $2.0-\mathrm{mm}$ system plates. A persistent bone defect in a region of the mandibular symphysis and parasymphysis was filled with bone grafts removed from the excess bone that had formed around the reconstruction plate. The postoperative period was uneventful. At 4 years of postoperative follow-up of the orthognathic surgery and 12 years of follow-up after CGCL resection, the patient had no signs of recurrence, and with good facial symmetry (Fig 7).

\section{Discussion}

Nonsurgical methods for the treatment of CGCL are of great importance, mainly because the prevalence of this lesion is greater in young people and the treatment can alter the development of the jaws and cause important aesthetic disfigurations. These treatments can achieve complete resolution of the lesion; however, in some cases, a bone defect can persist, requiring bone osteoplasty. In cases of partial resolution of the lesion, surgical curettage is usually used as the additional treatment. ${ }^{5}$

The first reported use of intralesional corticosteroids for CGCLs was reported by Terry and Jacoway ${ }^{12}$ in 1994. They adopted the use of a 1:1 solution of triamcinolone acetonide $10 \mathrm{mg} / \mathrm{mL}$ and $0.5 \%$ bupivacaine (Marcaine) to treat 5 cases of CGCL. The protocol originally proposed performing 6 weekly applications; however, this cycle can be repeated. In the present case, a new cycle was not performed because the lesion had continued to grow without 

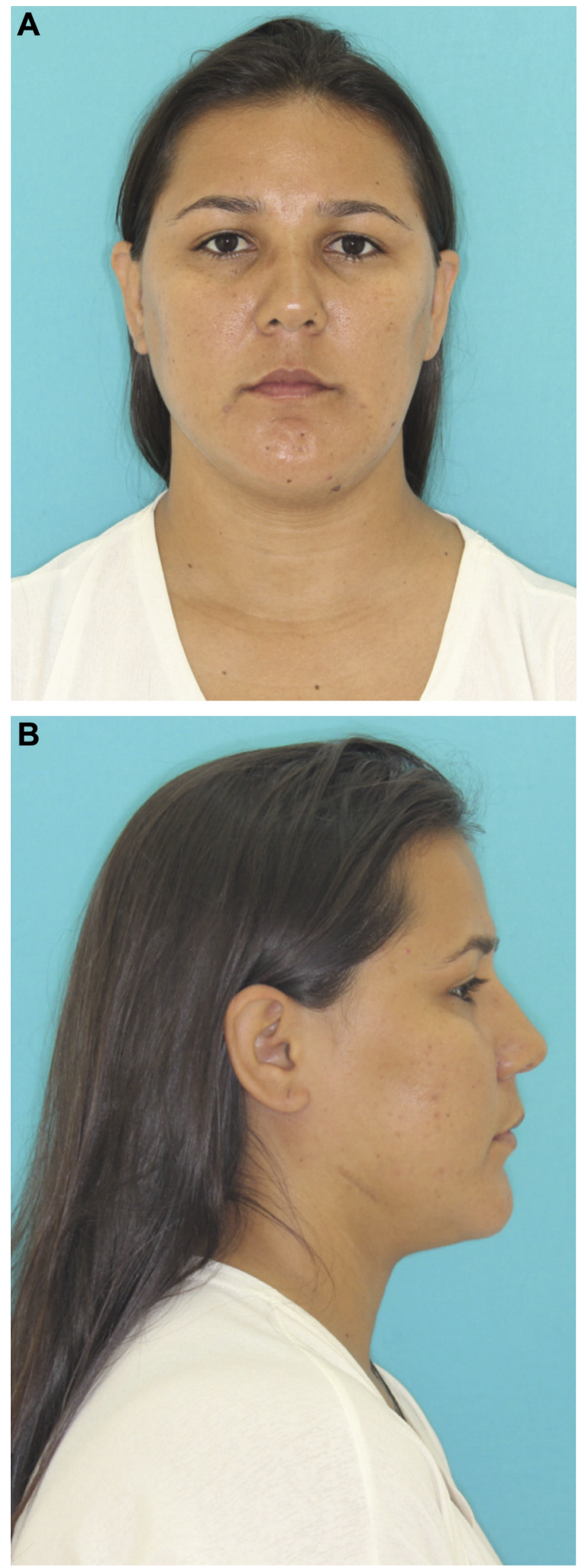

FIGURE 7. $A$ to $D, F$, Views at 4 years after bilateral sagittal split ramus osteotomies, with no signs of recurrence of central giant cell lesion, with good symmetry. E, Sagittal slice of a cone beam computed tomography scan showing bone filling in area of previous bone defect.(Fig 7 continued on next page.)

Maia Nogueira et al. Treatment of CGCL. J Oral Maxillofac Surg 2016. any sign of a response to treatment. The present case was one that had responded negatively to corticosteroid injections in our previous study ${ }^{5}$ (case 12 in the previous study), and a previous immunohistochemical analysis for glucocorticoid receptors (GRs) showed that an $\mathrm{H}$-score greater than 48 in MGCs predicts a good response to treatment. ${ }^{13}$ In the present patient, the H-score for GRs was 24, lower than that of patients with a good response to treatment and could explain the negative treatment response. In cases of failure of intralesional corticosteroid injections, a new therapeutic strategy should be adopted. For the present patient, the use of calcitonin was chosen.

Calcitonin inhibits osteoclastic activity, increases the influx of calcium in the bones, and antagonizes parathyroid hormone, with consequent bone formation and calcification. As osteoclasts, the MGCs of CGCLs present with calcitonin receptors ${ }^{14}$; thus, they show inhibition of activity during systemic use of calcitonin. The most widely used systemic calcitonin is salmon calcitonin, which is more potent than human calcitonin and is given as a daily dose nasal spray (200 IU/day) or subcutaneous injection (100 IU/ day). The recommended treatment duration is approximately 12 months; however, cases with 36 months of treatment have been reported. ${ }^{15}$ In the repair of CGCLs after the use of calcitonin, the newly formed bone can present with similarities in imaging, with fibro-osseous lesions representing only reactive bone without pathologic signs on histopathologic examination. ${ }^{15}$ Changes in the radiographic pattern of the lesion are expected to be present within a 6-month period with the use of calcitonin. In the present patient, no clinical or radiographic changes in the lesion were seen; therefore, a new approach was needed.

Other nonsurgical treatment with denosumab or surgical enucleation with adjuvant interferon therapy could be considered for cases such as the present case. Denosumab is a human monoclonal antibody that inhibits RANKL. RANKL is a bone resorption regulator that stimulates osteoclast differentiation and proliferation; therefore, denosumab inhibits the formation, function, and survival of osteoclasts, decreasing bone resorption. ${ }^{16}$ The first 2 reports of the use of denosumab for CGCL were only in $2014^{9,10}$ and it was not an option for our patient. To date, few cases have been reported in published studies and all achieved a cure ( 2 years disease-free) or remission (<2 years disease-free) of the CGCL. ${ }^{9-11}$ As reported by Tarsitano et $\mathrm{al}^{17} 2016$, denosumab is a potential pharmacologic treatment alternative for aggressive cases of CGCL; however, the role of denosumab in the occurrence of drug-induced osteonecrosis of the jaws must be highlighted.

Interferon is an antiangiogenic drug first used by Kaban et $\mathrm{al}^{6} 1999$ to treat CGCLs. They hypothesized that 

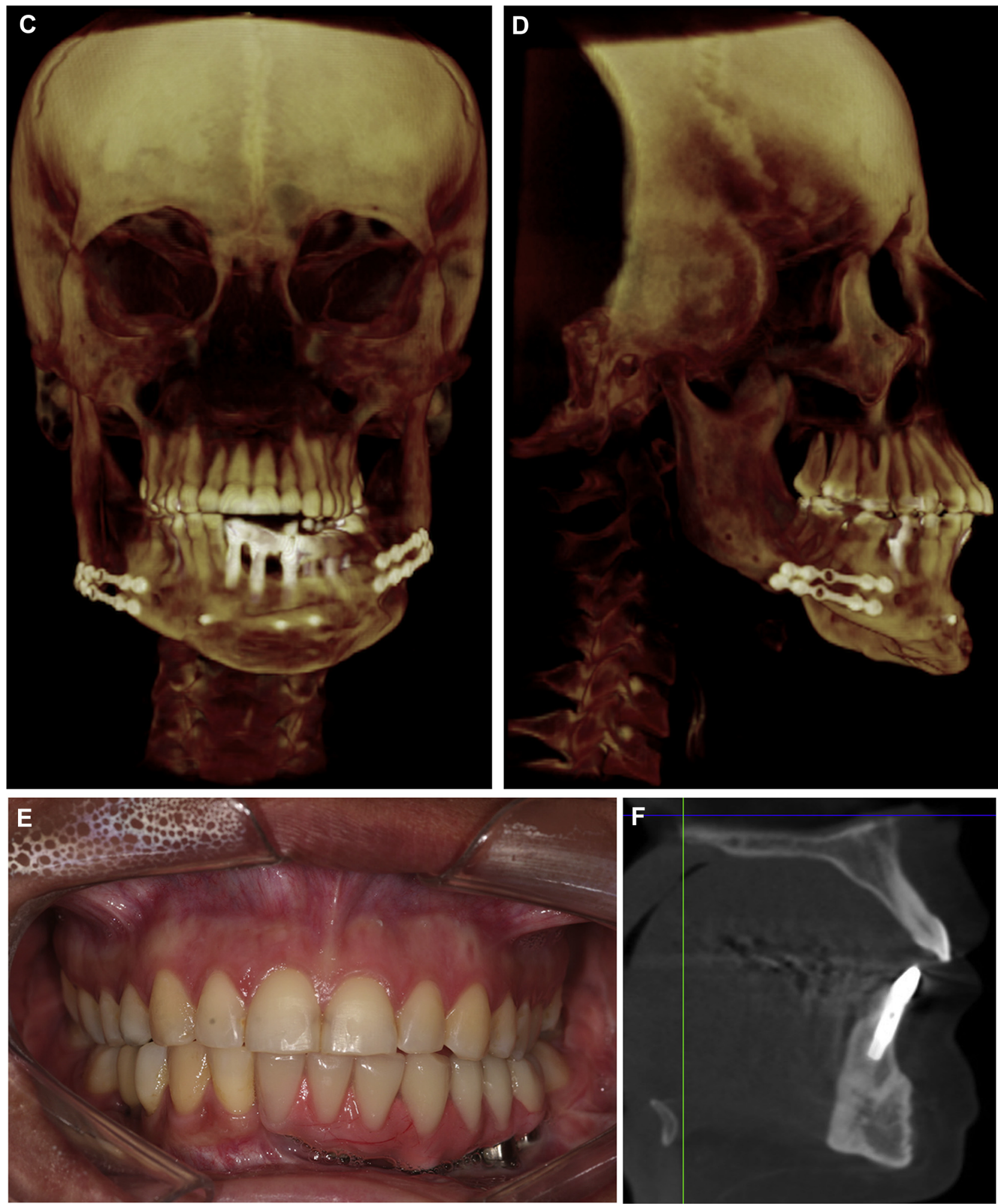

FIGURE 7 (cont'd).

Maia Nogueira et al. Treatment of CGCL. J Oral Maxillofac Surg 2016.

CGCLs were proliferative vascular lesions or at least angiogenesis-dependent lesions and, therefore, could be expected to respond to interferon. ${ }^{6}$ Kaban et al ${ }^{7}$ in 2007 , and other researchers, ${ }^{18,19}$ successfully used the combination of curettage followed by daily subcutaneous injections of interferon-alfa to treat 
aggressive CGCLs. The combined treatment seemed to be more successful than corticosteroid injections for aggressive CGCLs. Kaban et $\mathrm{al}^{7}$ showed that all cases treated by surgery combined with interferon were cured or in remission.

By the time of failure of calcitonin in the present patient, the remaining options were surgical resection or surgical curettage combined with interferon. Because both options included surgery, en bloc resection, as the reference standard treatment, was chosen.

Surgical treatment can range from simple curettage to en bloc resection with loss of a mandibular segment; the recurrence rates differ depending on the surgical technique used. Nonaggressive small lesions can be treated by curettage with low recurrence rates; however, multilocular lesions with limited surgical access, cortical bone perforation, and the presence of teeth can make curettage difficult and increase the risk of recurrence. Surgical resection has the lowest recurrence rate but the greatest morbidity. It usually causes significant facial disfigurement, requiring extensive and time-consuming bone reconstruction ${ }^{20}$ and incurs high costs for rehabilitation. In the present case, because of the lack of a response to nonoperative treatments, surgical resection was performed, with mandibular reconstruction performed later.

Small alveolar reconstruction can be performed using the techniques of guided bone regeneration. However, because of the extent of the bone defect in the present case, guided bone regeneration was not used, and autogenous bone grafting was elected. Autogenous bone graft is considered the reference standard, but some amount of bone resorption is still expected after grafting. Some cases could require a second reconstructive technique such as distraction osteogenesis to obtain a satisfactory bony height before implant placement. ${ }^{20}$ In the present patient, the first bone graft was performed with the aim of obtaining sufficient bone for implant placement in the proper position. The second graft was performed to fill the bone defect of the symphysis and parasymphysis. Finally, orthognathic surgery was performed to correct the laterognathia; this procedure is a wellaccepted treatment modality and is used for the resolution of dentoskeletal deformities, such as in the present patient.

In conclusion, treatment of CGCL using pharmacologic techniques can be considered the first therapeutic option, especially for extensive cases in which surgical treatment would cause significant tissue damage. In cases of pharmacologic treatment failure, more invasive treatments will be required. The bone defects caused by these techniques usually require multiple steps for rehabilitation, resulting in high costs for treat- ment. Additionally, long-term follow-up should be emphasized for such patients because of the possible recurrence of the CGCL.

\section{References}

1. Kruse-Lösler B, Diallo R, Gaertner C, et al: Central giant cell granuloma of the jaws: A clinical, radiologic, and histopathologic study of 26 cases. Oral Surg Oral Med Oral Pathol Oral Radiol Endod 101:346, 2006

2. Chuong R, Kaban LB, Kozakewich H, Perez-Atayde A: Central gi ant cell lesions of the jaws: A clinicopathologic study. J Oral Maxillofac Surg 44:708, 1986

3. Unal M, Karabacak T, Vayısoglu Y, et al: Central giant cell reparative granuloma of the mandible caused by a molar tooth extrac tion: Special reference to the manuever of drilling the surgical field. Int J Pediatr Otorhinolaryngol 70:745, 2006

4. de Lange J, Rosenberg AJWP, van den Akker HP, et al: Treatment of giant cell granuloma with calcitonin. Int J Oral Maxillofac Surg 28:372, 1999

5. Nogueira RL, Teixeira RC, Cavalcante RB, et al: Intralesional in jection of triamcinolone hexacetonide as an alternative treat ment for central giant-cell granuloma in 21 cases. Int J Oral Maxillofac Surg 39:1204, 2010

6. Kaban LB, Mulliken JB, Ezekowitz RA, et al: Antiangiogenic therapy of a recurrent giant cell tumor of the mandible with interferon alfa-2a. Pediatrics 103:1145, 1999

7. Kaban LB, Troulis MJ, Wilkinson MS, et al: Adjuvant antiangiogenic therapy for giant cell tumors of the jaws. J Oral Maxillofac Surg 65:2018, 2007

8. Kaban LB, Troulis MJ, Ebb D, et al: Antiangiogenic therapy with interferon alpha for giant cell lesions of the jaws. J Oral Maxillofac Surg 60:1103, 2002

9. Naidu A, Malmquist MP, Denham CA, Schow SR: Management of central giant cell granuloma with subcutaneous denosumab therapy. J Oral Maxillofac Surg 72:2469, 2014

10. Schreuder WH, Coumou AW, Kessler PA, de Lange J: Alternative pharmacologic therapy for aggressive central giant cell granuloma: Denosumab. J Oral Maxillofac Surg 72:1301, 2014

11. O'Connell JE, Bowe C, Murphy C, et al: Aggressive giant cell lesion of the jaws: A review of management options and report of a mandibular lesion treated with denosumab. Oral Surg Oral Med Oral Pathol Oral Radiol 120:e191, 2015

12. Terry BC, Jacoway JR: Management of central giant cell lesionsAn alternative to surgical therapy. Oral Maxillofac Surg Clin North Am 6:579, 1994

13. Nogueira RL, Faria MH, Osterne RL, et al: Glucocorticoid and calcitonin receptor expression in central giant cell lesions: Implications for therapy. Int J Oral Maxillofac Surg 41:994, 2012

14. Vered M, Buchner A, Dayan D: Immunohistochemical expression of glucocorticoid and calcitonin receptors as a tool for selecting therapeutic approach in central giant cell granuloma of the jawbones. Int J Oral Maxillofac Surg 35:756, 2006

15. Sadiq Z, Goodger NM: Calcitonin-induced osteoplastic reaction in the mandible. Br J Oral Maxillofac Surg 49:578, 2011

16. Sinningen K, Tsourdi E, Rauner M, et al: Skeletal and extraskeletal actions of denosumab. Endocrine 42:52, 2012

17. Tarsitano A, Del Corso G, Marchetti C: In reply. J Oral Maxillofac Surg 74:873, 2016

18. O'Connell JE, Kearns GJ: Aggressive giant cell granuloma of the jaws treated with interferon alpha: A report of two cases. Ir J Med Sci 182:163, 2013

19. Tarsitano A, Del Corso G, Pizzigallo A, Marchetti C: Aggressive central giant cell granuloma of the mandible treated with conservative surgical enucleation and interferon- $\alpha$-2a: Complete remission with long-term follow-up. J Oral Maxillofac Surg 73: 2149, 2015

20. de Moraes M, Sato FRL, Germano AD, Bastos PL: Distraction osteogenesis of iliac bone graft as a reconstruction after central giant cell granuloma curettage. Implant Dent 18:126, 2009 